\title{
NOTAS SOBRE LA OBJECIÓN DE CONCIENCIA Y LA VENTA DE PRODUCTOS FARMACÉUTICOS
}

La Dirección de la Revista Chilena de Derecho invitó a participar en la sección de Ensayos y Crónicas a los profesores de Derecho: Javier Couso ${ }^{1}$ y Matías Guiloff ${ }^{2}$, de la Universidad Diego Portales, y Rodrigo Delaveau ${ }^{3}$, de la Pontificia Universidad Católica de Chile, para que cada equipo respondiera tres preguntas relativas a un tema que despertó gran interés en el medio jurídico nacional. Se trataba, en efecto, de la negativa de venta de un fármaco en farmacias nacionales y el argumento sobre la objeción de conciencia, de acuerdo al Art. 19 No 6 de la Constitución Política de la República, invocado como una razón que justificaría tal negativa de comercialización.

Sin perjuicio de la forma en que dicha situación puntual llegue a resolverse, la materia es de interés actual y se proyecta a múltiples instancias.

El resultado de este ejercicio fue el siguiente:

\section{En materia farmacéutica, ¿cabe hacer objeción de conciencia, de acuerdo al Art. 19 No 6 de la Constitución Política de la República?}

J. C. y M. G: "El debate surgido a propósito de la distribución en las farmacias nacionales de la denominada 'pildora del día después' plantea una serie de cuestiones de carácter filosófico, constitucional, legal y reglamentario. En este breve texto, sin embargo, nos limitaremos a responder las muy precisas

${ }^{1}$ Javier Couso, Abogado Universidad Católica de Chile, Ph.D. en Jurisprudence and Social Policy, Universidad de California-Berkeley, Master (M.A.), en Jurisprudence and Social Policy, Universidad de California-Berkeley, Profesor de Derecho, Universidad Diego Portales.

2 Matías Guiloff, Magíster en Derecho Universidad de Columbia, U.S.A., Profesor de Derecho, Universidad Diego Portales.

${ }^{3}$ Rodrigo Delaveau "Profesor Auxiliar Asociado de Derecho Constitucional, Facultad de Derecho Pontificia Universidad Católica de Chile. preguntas planteadas por los editores de la $R e$ vista Chilena de Derecho y en el espacio de la sección de la Revista destinada a ello.

"Hemos comenzado analizando el contexto regulatorio de la actividad farmacéutica en Chile, en particular, si el Estado tiene facultades legales y reglamentarias para obligar a quienes deseen incorporarse a dicha actividad económica a tener a disposición del público la mencionada píldora. Esto es importante para el desarrollo del argumento central, que defiende la idea que siendo la actividad farmacéutica una que provee bienes públicos básicos, y no estando nadie obligado a participar en ella, el gobierno puede imponer a las farmacias la obligación de poner a disposición del público determinados medicamentos, incluida la píldora del día después. Por lo dicho, si alguna persona siente que esta carga la obliga a violar sus principios o sus creencias debiera abstenerse de entrar o de seguir en esta actividad. De otra manera, un aspecto tan fundamental para las políticas públicas de salud, como lo es el asegurar a la población la provisión de medicamentos, quedaría entregado a la voluntad de cada individuo".

R. D: "En primer lugar, la 'objeción de conciencia' y la 'libertad de conciencia', consagrada esta última en el Art. 19 No 6 de la Constitución Política, no son conceptos idénticos. La primera se considera como un rechazo al cumplimiento de determinadas normas jurídicas por ser estas contrarias a las creencias éticas o religiosas de una persona. Su expresión más común suele ser frente al servicio militar, no obstante poder plantearse hipotéticamente ante cualquier tipo de norma positiva. La segunda, en cambio, está configurada como una libertad o una garantía en el sentido liberal, como una libertad negativa, en virtud de la cual el Estado y terceros deben refrenarse de ejercer actos u omisiones que perturben el pleno ejercicio de este derecho, relacionado preferentemente con el ejercicio del culto y la religión.

"Si bien el iusnaturalismo considera que existe un orden normativo superior al Derecho 
positivo, la objeción de conciencia se encapsula como una facultad de resistir los mandatos de la autoridad cuando contradicen los principios emanados del Derecho natural. También la Declaración Universal de los Derecho del Hombre, que la define como resistencia a la opresión, reconoce ciertos límites. Luego, si el ordenamiento jurídico no contempla mecanismo para hacer valer este derecho, si no se dispone de un sistema normativo de protección de derechos esenciales, si no existe una judicatura, un debido proceso, e instrumentos formales para ejercer estas garantías, ni límite al gobernante, solo ahí estaremos en un escenario probable en que eventualmente pueda ejercerse este derecho. Pero definitivamente, este no es el caso chileno. Por el contrario, ha sido la propia Constitución la que ha trazado un orden institucional, un sistema de protección de derechos, un juego de pesos, contrapesos y límites al poder estatal, mecanismos formales y transparentes de formación de la ley y de judicatura independiente, donde todos quedan sometidos a su imperio. Es en definitiva, un Estado de Derecho.

"Aún así cabe preguntarse si ante la situación de que tres importantes cadenas de farmacias han sido sancionadas por la autoridad de salud por no contar en su stock con unidades de la 'píldora del día después', pueden invocar la denominada objeción de conciencia o la libertad de conciencia. La verdad es que ni la una ni la otra parecen salidas efectivas a este dilema, y están lejos de aportar mucho al debate, toda vez que se ha tornado una discusión 'moralista' a veces llamada 'valórica'. Y es que el ordenamiento institucional chileno entrega -afortunadamente- suficientes herramientas de solución. De ahí que el conflicto esté resuelto mucho antes a nivel legal y constitucional que, precisamente, nos alejan de un conflicto estéril”.

2. Estima usted que los propietarios y/o los farmacéuticos pueden hacer objeción de conciencia respecto de la venta de ciertos fármacos, incluidos los del Formulario Nacional?

J. C. y M. G: "Como se señaló en la sección anterior, el mercado farmacéutico se encuentra altamente regulado. En consecuen- cia, es uno en que los agentes económicos no gozan de libertad absoluta. La justificación para tan elevados niveles de regulación es el rol que juegan las farmacias en las políticas de salud que debe implementar el gobierno para cumplir con su deber de velar por la salubridad pública, así como el riesgo involucrado en la venta de medicamentos.

"Entre las numerosas disposiciones legales y reglamentarias que regulan la actividad de las farmacias se encuentran aquellas que prescriben el deber de las mismas de poner a disposición del público todos los medicamentos que se encuentren incluidos en el Formulario Nacional, como la píldora del día después. En primer término, cabe tener presente el artículo $100 \mathrm{del}$ Código Sanitario, que establece los deberes del Ministerio de Salud, entre los cuales se encuentra el aprobar un Formulario Nacional de medicamentos, para lo cual puede tomar las medidas necesarias para que la población se encuentre permanentemente abastecida de los productos farmacéuticos que lo componen.

"Esta disposición está complementada por los artículos 15, 92 y 93 del 'Reglamento de Farmacias, Droguerías, Almacenes Farmacéuticos, Botiquines y Depósitos', contenidos en el Decreto Supremo 466 del Ministerio de Salud. El primero de los artículos mencionados establece la obligación de las farmacias de contar de manera permanente con aquellos productos establecidos en el título IX de la misma regulación. El artículo 92 -que concretiza la obligación que el artículo 15 enuncia-, por su parte, dispone que las farmacias deberán contar permanentemente con aquellos productos que se encuentren contenidos dentro del Formulario Nacional, salvo las excepciones que se contemplan en el artículo 93, ninguna de las cuales dice relación con los productos que para efectos de este comentario interesan.

"En el mismo sentido, debe hacerse referencia a la disposición contenida en el artículo 4 del Decreto Supremo 264 del Ministerio de Salud, que reitera el deber de tener a disposición del público aquellos medicamentos que se encuentren contenidos en el Formulario Nacional, deber que se mantiene incluso cuando los medicamentos no se encuentren comercializados en el país, tratándose de situaciones excep- 
cionales y para los propósitos de usos medicinales urgentes. Así las cosas, debe concluirse que, estando un medicamento contenido en el Formulario Nacional, las farmacias no tienen otra opción que tenerlo a disposición del público. Tal es justamente la situación de la píldora del día después. Esta fue incluida en el Formulario Nacional en marzo de 2006 por medio del Decreto Supremo 194 del Ministerio de Salud. En concreto el DS 194 incluyó el levonorgestrel, principio activo de la píldora del día después, pasando esta a constituir uno de aquellos medicamentos que permanentemente las farmacias deben poner a disposición del público.

"Con todo, frente a las disposiciones citadas más arriba se ha esgrimido por parte de quienes niegan la existencia de una obligación de las farmacias de vender la píldora del día después una contenida en el artículo 102 del Código Sanitario, que establece que ningún producto farmacéutico puede ser comercializado en el país sin estar previamente registrado en el Instituto de Salud Pública. En este sentido, los grupos mencionados han señalado que la distribución de la píldora (particularmente a través del producto Optinor) por parte de la Central Nacional de Abastecimiento y la ONG Aprofa no cumpliría con todos los requisitos legales, por cuanto Optinor hasta el día de hoy no cuenta con registro sanitario.

"El problema con esta argumentación es que no considera que el inciso segundo de la normativa citada contempla la posibilidad que la autoridad sanitaria establezca autorizaciones provisorias para poder vender o usar productos farmacéuticos, sin necesidad de previo registro, para usos medicinales urgentes, de investigación científica o de ensayos clínicos. Cabe señalar adicionalmente que a la fecha el producto Pregnon del Laboratorio Family Care cuenta con registro sanitario, por lo que la distribución de la píldora del día después se encuentra en la situación normal prevista por la ley.

R. D: "Antes de invocar cualquier objeción, debemos preguntarnos si el Estado tiene o no derecho para imponer esa medida. En una sociedad de libertades, el Estado tiene límites. El surgimiento del Estado de Derecho moderno (y del Constitucionalismo) tiene, entre sus ra- zones principales, la protección del individuo frente al poder ilimitado que solía ejercer el rey o el Estado. En este contexto, el Derecho se levanta como la principal garantía que obliga tanto a gobernados como a las autoridades en el ejercicio de sus poderes. El Estado solo podría obligar a una persona a hacer aquello que esta no desea si una ley lo establece. Así ocurre a diario en nuestras vidas -quizás más de la cuenta- cuando el Estado nos obliga a pagar impuestos, realizar trámites, celebrar cierto tipo de contratos con cláusulas a las que no podemos renunciar, etc. De ahí que el argumento de la objeción de conciencia no sea solo equivocado e infundado, sino que sumamente peligroso, ya que podría 'autorizar' a cualquier grupo o persona a desobedecer una ley legítima. Más aún ¿qué sucedería si el gobernante invocara 'una objeción de conciencia' frente a una norma constitucional y decidiera ejercer el poder a su arbitrio? Así las cosas, no pareciera ser que la denominada objeción de conciencia sea el eje de la discusión en este caso. No obstante, son otras las disposiciones constitucionales las que están en juego y que aportan un principio de solución a este debate.

"La pregunta siguiente es entonces si la ley permite en este caso concreto que el Estado exija la venta de ciertos medicamentos. El artículo 100 del Código Sanitario dispone que 'El Ministerio de Salud Pública aprobará (...) un Formulario Nacional de Medicamentos que contendrá la nómina de los productos farmacéuticos indispensables en el pais para una eficiencia terapéutica'. Luego agrega que el 'Director General de Salud dispondrá las medidas necesarias para que la población y los servicios que presten atención médica se encuentren permanentemente abastecidos de los productos farmacéuticos que componen el Formulario Nacional de Medicamentos'.

"Como puede apreciarse, esta norma no establece directamente la obligación de que sean las farmacias las que cuenten con esos fármacos, sino que obliga al Director General de Salud a procurar la disponibilidad de tales insumos, cuestión que naturalmente debe hacer en el marco de sus facultades legales. En este sentido la norma parece perfectamente enmarcada en un sistema donde el Estado cumple un rol subsidiario, donde prima la persona. Con todo, 
las normas que efectivamente establecen la obligación a las farmacias de contar con los productos incluidos en el Formulario Nacional son el artículo 92 del 'Reglamento del Farmacias, Droguerías, Almacenes Farmacéuticos, Botiquines y Depósitos Autorizados', y el artículo $4^{\circ}$ del 'Reglamento del Formulario Nacional de Medicamentos'. Ambas normas no tienen rango de ley, sino que emanan de la potestad reglamentaria de la autoridad.

"Acá radica el corazón de la protección a los individuos: la formación de la ley, a través de un proceso público donde están los representantes del pueblo (lo que desligitima -en parte- el argumento de la objeción de conciencia), es un proceso que, si bien no es perfecto, entrega mayores garantías a las personas en cuanto a asegurarle, al menos, un espacio para alegar la protección de sus derechos: la ley es una garantía en sí misma. En cambio, la dictación de un reglamento es tradicionalmente una cuestión sin procedimientos abiertos ni instancias de discusión que transciendan a la opinión pública. Adicionalmente, conviene considerar que siempre en los decretos hay mayor espacio a la discrecionalidad. En efecto, bastaría con un simple decreto para incluir nuevos productos farmacéuticos en el Formulario Nacional. Esto puede generar situaciones complejas como la de pretender gravar a una farmacia con la obligación de tener en existencia medicamentos de alto costo que hagan inviable la continuidad del negocio, lo cual vulneraría no solo la capacidad financiera de un particular, sino que la propia libertad de empresa y la igualdad ante las cargas públicas".

3. De acuerdo a su pensamiento, jexiste en este caso un conflicto entre libre empresa y concepto de servicio público?

J. C. y M. G: "El Ministerio de Salud tiene facultades legales y reglamentarias para obligar a quienes deseen operar en el negocio farmacéutico a poner a disposición del público la píldora del día después. En lo que sigue, revisaremos si los propietarios y/o los farmacéuticos pueden hacer objeción de conciencia respecto de la obligación legal de vender dicho medicamento.
"En primer término, es importante precisar que más que un caso de objeción de conciencia, la coordinación de algunos sectores para intentar que las farmacias no vendan la píldora del día después representa una instancia de 'desobediencia civil' y no de 'objeción de conciencia'. En efecto, y como lo señala Ernesto Garzón Valdés ('Acerca de la desobediencia civil', Sistema, $\mathrm{N}^{\circ} 42$, mayo, pp. 80 y ss.,), la objeción de conciencia es un acto personal, que por lo general no busca modificar las leyes, sino circunscribir la desobediencia al caso particular. El ejemplo paradigmático de este tipo de conductas es el del pacifista o miembro de credos religiosos opuestos a la guerra que es obligado a servir en el servicio militar, y que prefiere soportar el castigo por incumplir con su obligación legal a violar su conciencia. Este caso es en efecto muy distinto a la acción concertada de sectores del país que, habiendo fracasado en su intento de prevalecer legislativamente, buscan ahora que sus opciones de política pública prevalezcan por otras vías.

"En todo caso, aun si se considerara que lo que ocurre en Chile en relación a la píldora del día después representa un caso genuino de objeción de conciencia (y no de desobediencia civil), el hecho que a diferencia del servicio militar obligatorio la ley en el caso de la píldora no imponga a nadie la obligación de operar establecimientos farmacéuticos hace improcedente alegar la objeción de conciencia.

"Finalmente, y en relación al potencial conflicto entre libre empresa y el concepto de servicio público que algunos advierten en relación con la obligación impuesta por el Ministerio de Salud a las farmacias de poner a disposición del público la píldora del día después, nos parece que este no existe, dado que el concepto de libre empresa no puede extenderse al punto de hacer inoperantes regulaciones plenamente justificadas desde el punto de las políticas de salud pública, atendido el crucial rol que juegan las farmacias en la consecución de las mismas. Por otra parte, si se aceptara la tesis de la primacía de la libre empresa por sobre la función pública, el gobierno estaría plenamente justificado en establecer farmacias estatales en cada uno de los municipios del país. 
R. D: "La Constitución ha entendido que para regular una actividad económica deber ser la ley el instrumento elegido por la autoridad y no decisiones reglamentarias que no entregan garantías suficientes del respeto a los derechos fundamentales. No debe olvidarse que la imposición de la autoridad puede generar responsabilidades legales para las farmacias. En efecto, la ley de Protección al Consumidor dispone que son responsables por los perjuicios ocasionados al consumidor, el proveedor que haya comercializado el producto y el importador que lo haya vendido. Difícil resulta aseverar que si se exige a las farmacias indemnizar los daños causados por un aborto producido por la píldora, vendrá el Estado en defensa de las farmacias argumentando que fueron obligadas a distribuirla. Así, la obligación que quiere imponer el Gobierno se sostiene sobre cuestionables bases jurídicas pues no solo carece de ley que lo autorice a hacerlo, sino que además atenta contra el derecho que tienen los gobernados a ejercer una actividad económica.

"¿Es entonces un conflicto entre libre empresa y concepto de 'servicio público'? Aun en el caso hipotético que fuera la ley la que obliga a las farmacias a vender los medicamentos que la autoridad determina, hay límites que deben respetarse. Y es aquí donde debiera centrarse lo relevante de la discusión: la libertad de empresa y el derecho a ganarse la vida honradamente, solo pueden limitarse por la Constitución o una ley, no por decreto. Los derechos a emprender y el de propiedad, no pueden ser limitados al punto de despojar al propietario o al emprendedor del núcleo esencial de esos derechos.

"Desde el punto de vista de las políticas públicas, debe también considerarse la conveniencia de una decisión que quiere transformar a privados -que son parte de un mercado- en simples mandatarios del gobernante de turno. Esta lógica, típica de gobiernos paternalistas, no se condice con una sociedad libre, donde si la población demanda el medicamento, naturalmente surgirá la oferta. No basta con argumentar, como se ha dicho, que los privados están ejerciendo una función pública. Si el Gobierno considera de suma importancia la repartición de un medicamento, debe tomar las medidas para que ello ocurra (distribuyéndolo él mismo, si lo estima necesario) pero sin dañar los derechos de las demás personas, ni desdibujar su rol subsidiario y respetuoso de la iniciativa y responsabilidad individual. En cualquier democracia moderna en que exista un aparente conflicto de derecho, existen los mecanismos jurídicos y judiciales para resolver dicha contienda.

"Lo que no resulta admisible en un Estado de Derecho es que el gobernante de turno utilice un subterfugio legal, al calificar a la 'píldora' como un medicamento, cuando es claro que el embarazo no constituye ninguna enfermedad. La autoridad ha intentado llevar la discusión a hacia un terreno pantanoso, que siempre genera polémica y tributa objetivos políticos como la denominada 'objeción de conciencia', señalando que lo que 'importa es la libertad de conciencia de las personas para tomar sus propias decisiones y no la de los dueños de las farmacias' (El Mercurio, 30 de octubre de 2007). Sin perjuicio que pareciera decir la autoridad que los propietarios de las farmacias no pueden ejercer entonces su libertad de conciencia, lo cierto es que la discusión pasa por saber si la autoridad actuó respetando la ley (primera garantía para las personas) y de si existe el derecho de las personas a ejercer un actividad comercial de la manera que lo estimen conveniente, sin restricciones discrecionales por parte del gobernante.

"El modus operandi de la autoridad no deja de ser preocupante: sin ley alguna se quiere obligar a algunos a actuar según lo determine el gobierno de turno, sin respeto a los derechos individuales. Más allá -o más acá- que un debate sobre objeción de conciencia, deberíamos ser capaces de encontrar mecanismos formales para ejercer uno de los más fundamentales derechos de toda democracia moderna: la facultad de defendernos de gobernantes que asuman poderes no asignados por los gobernados". 